\title{
Review of eye-tracking: A neuromarketing technique
}

\author{
Chiemelie Benneth Iloka* and Grace Ifeoma Anukwe \\ Enugu State University of Science and Technology (ESUT), Enugu State, Nigeria \\ * Correspondence: ilokaben@gmail.com or iloka.benneth@esut.edu.ng; Tel.: +2348140766160
}

\author{
Received: 27 October 2020; Accepted: 31 December 2020; Published: 31 December 2020 \\ Edited by: Aida Azlina binti Mansor (Universiti Teknologi MARA, Malaysia) \\ Reviewed by: Vimala Venugopal (Taylor's University, Malaysia); \\ Muhamad Kamal Mohammed Amin (Universiti Teknologi Malaysia, Malaysia) \\ https://doi.org/10.31117/neuroscirn.v3i4.61
}

\begin{abstract}
Following technological advancements, the marketing world has witnessed a tremendous introduction of technologies that aid decision making. The essence is that through the adoption of such technologies, the marketers will make more informed decisions. Neuromarketing is a new marketing field that has witnessed increased penetration of technologies. As a field, it is centred on understanding the human brain's functionality when exposed to marketing activities. This article reviews eye-tracking as a neuromarketing tool. The review represents ideas from different scholars concerning the topic, concisely condensed to form the views held in this article. Findings from the review show that eye-tracking is one of the most commonly adopted neuromarketing tools because it is easier to access and implement with other tools. On the same note, some limitations come with this tool. The review concluded by stating that the best results with eye-tracking are obtained when combined with other tools to overcome these limitations and produce more informed data for better decisions and customer service.
\end{abstract}

Keywords: eye-tracking; marketing; neuromarketing; neuroscience;

C2020 by lloka \& Anukwe for use and distribution in accord with the Creative Commons Attribution (CC BY-NC 4.0) license (https://creativecommons.org/licenses/by-nc/4.0/), which permits unrestricted non-commercial use, distribution, and reproduction in any medium, provided the original author and source are credited.

\subsection{INTRODUCTION}

As Iloka and Onyeke (2020) pointed out, there has been significant growth in interest in the use of brain imaging techniques in the past years. These techniques are used to analyze the response of the brain to different circumstances. The authors went further by stating that scientific developments in recent years, which is more of an extension of how these techniques are applied in diverse and multidisciplinary research areas, have risen to address the issues that have been raised in these scientific fields. In any case, researchers have found this recent increase in the application of neuroscientific methods (neuroscience) to understand human behaviour across different interesting and exciting contexts. The term "neuromania" was first coined by Tallis and Taylor (2011), describing the various fields of study where neuroimaging applications are being used to study all manners of human behaviour related to activities within the brain.

Industrial science is a new and emerging area of neuroscience. Modern approaches are used in real contexts to attend to consumers' cognitive and emotional state (Borghini et al., 2017). Studies show that the financial sector was the first to employ these new techniques, ushering in neuroscience labs in this sector, with the central aim of attending to questions and issues raised concerning economic transactions. On that note, earlier researchers stated that it is essential for neuroscience researchers to align themselves with 
economists; to evaluate the activities of the brain on issues related to monetary value and judgment, to understand the major approaches that consumers employ in the course of making financial-related decisions (Cherubino et al., 2015). There has been a noticeable increase in the number of new studies within neuroscience, and these studies employ contemporary tools in neuroimaging to solve issues (Camerer et al., 2004; Glimcher \& Rustichini, 2004).

As stated by lloka and Onyeke (2020), one of the most commonly featured questions in marketing today is: what drives consumers to choose a given product instead of another, or what factors influence how consumers interact with a given brand? The need to answer this question has increased interest in understanding how the brain reacts during decisionmaking. Additionally, answering this question has increased the adoption of neuroscientific neuroimaging tools in a real-life setting; to study body stimuli, this is the main idea in industrial neuroscience. Before illustrating the concept further, it is essential to understand what neuromarketing is all about.

Neuromarketing is a term used to describe the field of study where neuroscientific methods are used to study and analyze human behaviours with a focus on markets and marketing exchanges (Lee et al., 2007). From this definition, there are two main highlights as: (1) there is a noticeable shift of consideration from neuromarketing centring on the adoption of neuroimaging as its interests are commercialized to benefit other users; and (2) the scope of neuromarketing is broadened to focus on the behaviour of consumers which include other exciting areas (such as inter- and intra-organizational research), and these new areas are common domain in the marketing field. Essentially, lloka and Onyeke (2020) stated that neuromarketing's main objective is to understand consumer behaviour from their subconscious level, eliminating biases associated with understanding such behaviour from their conscious level. Therefore, this paper aims to critically discuss the eye-tracking technique as a neuromarketing tool, highlighting how it's applied, associated limitations and ways to enhance its general application.

\subsection{EYE-TRACKING: LOOKING THROUGH THE EYES OF THE CONSUMERS}

Campos (2017) stated that as the name implies, eye tracking is all about studying people's eye movement and analyzing their behaviour based on this movement. That is to say, eye-tracking tools are the ones that make it possible for brands to see through the eyes of their potential customers, not just within lab-based scenarios, but also in the course of their actual real-life purchasing.

In the present day, eye tracking devices are tiny with lights, and participants can wear them while shopping or watching TV. Once the customer is wearing this device, brands can use data generated to answer a series of questions related to:

- The level of attention consumers attaches to the items being promoted near the store's entrance.

- Whether customers read billboards and posters, or they glance at the information present without reading.

- How customers attention are distributed when choosing products from shelves.

- The extent of attention consumers pays to ad placements on their television.

Eye-tracking does open a wide range of opportunities for marketing studies. Farnsworth (2019) demonstrate the application of this in advertising by referencing the case of companies attempting to boost sales for baby products by using close-ups of adorable faces of babies. Researchers discovered that when the baby looks face on, the focus of the viewers will be on the face of the baby, paying less attention to the product being advertised; however, when the baby is gazing at a product or text, the viewers will shift their focus to the content of the advertisement (Farnsworth, 2019). Dooley (2019) stated that as a result of this finding, companies put close up videos of adorable babies and make sure that the baby is looking at what they want the consumers to buy.

The eye-tracking technique measures the fixation or gazing (where the person is looking) point, the time that the person stared at the point, eye movement with the head, number of blinks, and dilation of the pupil (Zurawicki, 2010). Another evaluation that can be conducted in addition to the fixation is the sequence in the shift of the person's eye from one location to another (saccade) (Chae \& Lee, 2013). For conducting such analysis, different technologies can be used to measure the eye's movement and the most common are those that measure the observation of controlled stimuli at fixed points in photos, videos, and other interaction that users have via a computer screen. More advanced technologies can be used to track the head's movement in a three-dimensional space based on an attached camera (Zurawicki, 2010). The implication is that the measurement process is very 
subtle, as there is limited or no interaction between the subjects and the researchers.

In eye-tracking types of equipment, studies, although not new, have offered different unique views from the dimension of neuromarketing. Together with the potential of eye-tracking, these studies have become increasingly relevant in the visual pollution of today's business world with interest in assessing customers' attention. There are numerous applications in today's business work, on the mechanisms that guide customers in selecting a particular point of interest in an image (the standard of attention and forecasting places with the most significant interest) (Zhao \& Koch, 2013). As such, eye-tracking techniques can avail necessary information about the relevant items that involve attention, considering that it is related to visual fixation patterns, in different issues within the marketing context (Fiszman et al., 2013).

On the same note, the eye-tracking technique can be used together with other types of equipment to measure cognitive responses, the lead energy for new insights, with particular reference to consumers' behaviour and marketing communications. With the tool connected to facial coding, the results generated will show the accurate volume of visual activity (the exact point the person is looking at), linking specific emotional responses to different stimulated elements (people's feeling based on what they have seen).

With the emotional responses and visual focus synchronized, the marketer will access reliable data that can be used to understand the factors driving customers' reaction towards a given stimulus ( $\mathrm{Hill}$, 2011). The benefit of such is significant, especially when it comes to TV advertisements, with the vast amount of information generated in milliseconds, potentially limiting the ability to identify the main objects liked by the viewers, or the factors that drove their attention positively or negatively ( $\underline{\mathrm{Ho}, 2014})$.

There are two main models applied in eye movements being measured by the eye-trackers as fixation and saccades (Velásquez, 2013). Per Nielsen and Pernice (2009), fixation is all about the eye being fixed to a given object, enjoying the object's details; while, saccades is all about the rapid movement of the eye between two fixations. In addition to these major movements, eye trackers also measure variables that could be of great value for marketers, such as the size of the pupil (used for identifying attention and emotions), pupil dilation, and closure of the eyelids (used to monitor sleepiness) among other potential measures.

The range of eye fixation is usually approximated to be between $200 \mathrm{Ms}$ when reading a text, and $350 \mathrm{Ms}$ when viewing a scene. Scan path is the series of fixations and saccades produced through this eye movement. Interests, visual perceptions, cognitive intent, and relevance are analyzed through the scan paths. In the marketing context, one central area where the scan path analysis is applied is how humans interact with computers, especially when it comes evaluation of online advertisements and web pages (with the focal points of intention highlighted), and the behavioural patterns of navigation (Zurawicki, 2010). Chae and Lee (2013) also reported that other areas were eye-tracking techniques, such as recording and analyzing the individuals' visual attention by tracking their eyesight across different fields: marketing, usability, behavioural psychology, and cognitive psychology. This approach's potential is that it helps in identifying more effective ways of enhancing online sales and identifying the challenges that customer face in the process of checkout, either with the format employed or any of the steps followed in making such purchase (dos Santos et al., 2015).

In another argument, Orquín and Loose (2013) stated that the eye movement in the course of the decisionmaking process is as a result of the requirement of a given task and somewhat by the stimuli (that create biases to capture the information), which allows for striking visual stimuli to be favoured. The top-down and bottom-up factors aid attentions and influence how individuals interpret stimuli (Behe et al., 2013). As stated by Pieters and Wedel (2004), the bottom-up factors are features of the stimuli itself, representing a rapid form of attention being captured. On the other hand, top-down factors are the past (existing) ideas that the consumers already have about the product. When it comes to top-down factors, it is required that the consumers voluntarily search and pay attention to certain information about the product.

Although there have been many advances in technologies geared towards measuring the physiological signals of consumers, the less costly tools like facial coding and eye tracking have been embraced more by the neuromarketers (Harrell, 2019). Nielsen, a leading consultancy in the field of crowd marketing stated that using eye-tracking helps brands to make sure that the attention of customers is focused on the right things and at the right moments (for instance, 
when a logo appears), and a facial coding aimed at ensuring that the ad can trigger responses from the customers as it was designed to elicit (and it is essential to point out that Nielsen rarely uses any of its tools in isolation) (Harrell, 2019).

\subsection{CHALLENGES OF EYE-TRACKING}

Although the above discussions point out that the eyetracking system is interactive and straightforward, it is also essential to state that certain challenges come with such neuromarketing tools. They are as discussed below.

- On its own, eye-tracking tools cannot tell the user why someone is looking at a given point. The system can tell researchers what the person is looking at, but not necessarily how the viewer perceives the point being gazed at.

- On the second note, researchers cannot know whether a positive or negative emotional violence accompanies the visual attention.

- Another issue is that the web-cam applications of these tools are less precise and accurate when compared to the in-lab solutions.

- Eye-tracking systems are known to only record the centre of the person's visual gaze (known as foveal vision). They cannot record the periphery of an individual's visual gaze (known as profoveal vision). This is a critical limitation as the perception of objects in the periphery is usually below the conscious state, which can significantly affect the immediate reaction and subsequent behaviour of the individual (Yoo, 2009).

- By virtues of the above discussions, it is imperative that the actual meaning of fixation cannot be determined by focusing on eye-tracking alone. For instance, when a customer is going through a web page, the fixation might be a form of interest in a given area or indicate that they are having difficulties interpreting what is contained in the web page. Therefore, more prolonged fixation might be an indication of interest or goalrelevance. At the same time, it might be an indication of uncertainty or difficulty with processing the information. Similarity, shorter fixation might indicate lack of interest or boredom, or it might be associated with a higher level of processing fluency.

\subsection{ADDRESSING THE LIMITATIONS OF EYE-TRACKING}

Considering the above limitations, what can be deduced is that successful implementation of the eyetracking technique will depend on addressing these limitations. One of the ways would be to combine eye tracking with other methods. Facial expression coding is one of the most popular techniques that can be combined with eye tracking, allowing the marketer to measure emotional violence and fixations, gaze path, and pupil response when the customer is being exposed to marketing stimuli. This is also common in numerous software packages, combining eye-tracking with facial coding in a single system, making it possible for the user to capture and analyze two single data streams simultaneously.

The second approach would be to deploy eye-tracking alongside neurometric and biometric measures. The user will be able to augment the precision and accuracy that come with these measures. This is witnessed more in cases where the researcher's interest is to compare cognitive and emotional responses to different aspects of the visual scene, like print ad and web page.

The biometric features include psychological responses such as heart rate, respiration, and perspiration. They work together with the eye-tracking systems to offer evidence of emotional arousal to the focused attention. On the other hand, neurometrics are derived from functional magnetic resonance imaging (fMRI) or electroencephalography (EEG). The neurometrics are more complex than biometrics or facial coding in terms of implementation. They can still be combined with eye-tracking to go deeper into brain responses that come with visual attention, like motivation avoidance approaches, distraction, cognitive load, and stress (Ramsøy, 2015).

\subsection{CONCLUSION}

Essentially, this study has presented comprehensive review of eye-tracking, as a neuromarketing tool; highlighting its advantages and limitations in the process. Studies reviewed generally suggest that tools for measuring the physiological proxies about brain activities seem to be easier to use and more affordable. In the case of eye tracking, it can measure attention (through the fixation points of the eye) and arousal (through dilation of the pupil); facial-expression coding (this reads the minute movement of the muscles in the face) which measures emotional responses; and respiration rate, heart rate, and arousal measures of skin conductivity (

Given its rapidly decreasing price tag, intuitive metrics, the potential of turning things around fast, and the ability to be incorporated into software and hardware packages that are easy to use, eye-tracking will continue to be a widely used and easily available 
technique in the neuromarketing toolkits. However, there are certain limitations, and it is best used in combination with other approaches, instead of being standalone software (Genco, 2019). Notwithstanding these limitations, eye-tracking remain a crucial neuromarketing tool because of its advanced features and ease of applicability.
Acknowledgements: The study was funded by the authors.

Author Contributions: Both authors drafted and revised the entire work.

Conflicts of Interest: The authors declare no conflict of interest.

\section{References}

Behe, B. K., Zhao, J., Sage, L., Huddleston, P. T., \& Minahan, S. (2013). Display signs and involvement: The visual path to purchase intention. International Review of Retail, Distribution and Consumer Research, 23, 511-522. http://dx.doi.org/10.1080/09593969.2013.832695

Borghini, G., Aricò, P., Di Flumeri, G., \& Babiloni, F. (2017). Evaluation of Mental States in Aviation Personnel. Industrial Neuroscience in Aviation, 18, 83-113. https://doi.org/10.1007/978-3-319-58598-7

Camerer, C. F., Loewenstein, G., \& Prelec, D. (2004). Neuroeconomics: Why Economics Needs Brains. The Scandinavian Journal of Economics, 106(3), 555-579. http://www.jstor.org/stable/3441124

Campos, B. (2017, June 23). 5 neuromarketing techniques for marketers. Cyberclick. https://www.cyberclick.net/numericalblogen/5-neuromarketing-techniques-for-marketers

Chae, S. W., \& Lee, K. C. (2013). Exploring the effect of the human brand on consumers' decision quality in online shopping: An eye-tracking approach. Online Information Review, 37, 83-100. https://doi.org/10.1108/14684521311311649

Cherubino, P., Maglione, A. G., Graziani, I., Trettel, A., Vecchiato, G., \& Babiloni, F. (2015). Measuring Cognitive and Emotional Processes in Retail. In Successful Technological Integration for Competitive Advantage in Retail Settings (pp. 76-92). IGI Global. https://doi.org/10.4018/978-1-4666-8297-9.ch004

Dooley, R. (2019, June 10). Child Labor: Put That Baby to Work! Neuromarketing. https://www.neurosciencemarketing.com/blog/articles/baby-heat-maps.htm

dos Santos, R. d-O. J., de Oliveira, J. H., Rocha, J. B. \& Girald, J. d-M. E. (2015). Eye Tracking in Neuromarketing: A Research Agenda for Marketing Studies. International Journal of Psychological Studies, 7(1), 32-42. https://doi.org/10.5539/ijps.v7n1p32

Farnsworth, B. (2019, March 5). 15 Powerful Examples of Neuromarketing in Action. IMotions. https://imotions.com/blog/neuromarketing-examples/

Fiszman, B. P., Velasco, C., Salgado-Montejo, A., \& Spence, C. (2013). Using combined eye-tracking and word association in order to assess novel packaging solutions: A case study involving jam jars. Food Quality and Preference, 28, 328-338. https://doi.org/10.1016/i.foodqual.2012.10.006

Genco, S. (2019). What Eye-Tracking Can and Can't Tell You About Attention. Neuromarketing Science and Business Association. https://www.nmsba.com/buying-neuromarketing/neuromarketing-techniques/what-eye-tracking-can-andcant-tell-you-about-attention

Glimcher, P. W., \& Rustichini, A. (2004). Neuroeconomics: The consilience of brain and decision. Science, 306(5695), 447-452. https://doi.org/10.1126/science.1102566

Harrell, E. (2019, January 23). Neuromarketing: What You Need to Know. Harvard Business Review. https://hbr.org/2019/01/neuromarketing-what-you-need-to-know

Hill, D. (2011). Emotionomics: Leveraging emotions for business success (2nd ed.). London, United Kingdom: Kogan Page.

Ho, H. F. (2014). The effects of controlling visual attention to handbags for women in online shops: Evidence from eye movements. Computers in Human Behavior, 30, 146-152. http://dx.doi.org/10.1016/j.chb.2013.08.006

Iloka, B., C., \& Onyeke, K., J. (2020). Neuromarketing: a historical review. Neuroscience Research Notes, 3(3), 27-35. https://doi.org/10.31117/neuroscirn.v3i3.54

Lee, N., Broderick, A. J., \& Chamberlain, L. (2007). What is "neuromarketing"? A discussion and agenda for future research. International Journal of Psychophysiology, 63(2), 199-204. https://doi.org/10.1016/j.ijpsycho.2006.03.007

Nielsen, J., \& Pernice, K. (2009). Eyetracking web usability. In Berkeley. CA: New Riders.

Orquín, J. L., \& Loose, S. M. (2013). Attention and choice: A review on eye movements in decision making. Acta Psychologica, 144, 190-206. https://doi.org/10.1016/i.actpsy.2013.06.003

Pieters, R., \& Wedel, M. (2004). Attention capture and transfer in advertising. Brand, pictorial, and text-size effects. Journal of Marketing, 68(2), 36-50. https://doi.org/10.1509/jmkg.68.2.36.27794

Ramsøy, T. Z. (2015). Introduction to neuromarketing \& consumer neuroscience. Neurons Inc.

Tallis, R., \& Taylor, M. (2011). Neuromania? RSA Journal, 157(5547), 48. http://www.jstor.org/stable/41380121

Velásquez, J. D. (2013). Combining eye-tracking technologies with web usage mining for identifying Website Key objects. Engineering Applications of Artificial Intelligence, 26, 1469-1478. https://doi.org/10.1016/i.engappai.2013.01.003 
Yoo, C. Y. (2009). Unconscious processing of web advertising: Effects on implicit memory, attitude toward the brand, and consideration set. Journal of Interactive Marketing, 22(2), 2-18. https://doi.org/10.1002/dir.20110

Zhao, Q., \& Koch, C. (2013). Learning saliency-based visual attention: A review. Signal Processing, 93, $1401-1407$. https://doi.org/10.1016/j.sigpro.2012.06.014

Zurawicki, L. (2010). Neuromarketing: Exploring the brain of the consumer. Boston, MA: Springer. 